\section{Intoxicações provocadas por agrotóxicos de uso agrícola na microrregião de Dourados, Mato Grosso do Sul, Brasil, no período de 1992 a 2002}

\author{
Pesticide poisoning in Dourados, \\ Mato Grosso do Sul State, Brazil, 1992/2002
}

Dario Xavier Pires 1

Eloísa Dutra Caldas 2

Maria Celina Piazza Recena ${ }^{1}$

\footnotetext{
1 Departamento de Química, Universidade Federal de Mato Grosso do Sul, Campo Grande, Brasil. 2 Faculdade de Ciências da Saúde, Universidade de Brasília, Brasília, Brasil.

Correspondência D. X. Pires

Departamento de Química, Universidade Federal de Mato Grosso do Sul. C. P. 549, Campo Grande, MS 79070-900, Brasil.

msquim2001@yahoo.com.br
}

\begin{abstract}
Reports of poisoning and suicide attempts involving pesticides in the micro region of Dourados, Mato Grosso do Sul State, Brazil, from 1992 to 2002, were evaluated, using data from the Integrated Center for Toxicological Surveillance under the State Health Department. A total of 475 reports were made during the period, of which 261 were accidental or occupational poisonings, 203 suicide attempts, and 11 undetermined. Dourados county had the highest prevalence of pesticide poisoning and suicide attempts per 100,000 inhabitants, considering the rural population, and Fátima do Sul the second highest prevalence of suicides within the micro region. Significant correlations were found between poisoning and suicide $(r=0.60 ; p<0.05)$ and between poisoning and temporary crop area as a percentage of the county's total area $(r=0.68 ; p<0.05)$. Poisoning occurred predominantly in men (87.0\%), but the percentage of suicide attempts by men and women were similar (53 and 47.0\%, respectively). Poisonings occurred mostly from October to March and the organophosphate insecticides monocrotophos and methamidophos were the main pesticides involved.
\end{abstract}

Pesticides; Suicide; Poisoning

\section{Introdução}

Estima-se que milhões de agricultores são intoxicados anualmente no mundo e mais de 20 mil morrem em conseqüência da exposição a agrotóxicos, a maioria em países em desenvolvimento ${ }^{1}$. A falta de legislação e de controle do uso adequado destes produtos e o baixo nível de informação dos trabalhadores quanto aos riscos a que estão expostos são as principais causas destas ocorrências 2 . No Brasil, 26.164 casos de intoxicação provocados por agrotóxicos no campo ocorreram entre 1997 e 2001, correspondendo a 7,0\% do total de intoxicações notificadas no período (http://fiocruz.br/sinitox, acessado em 14/Set/2004).

Um mil trezentas e cinqüenta e cinco intoxicações devidas ao uso de agrotóxico de uso agrícola ocorreram no Mato Grosso do Sul, nono estado em área plantada no país, no período de 1992-2002 3,4. Dados, por nós não publicados, indicam que a microrregião de Dourados, a maior produtora agrícola e a segunda maior cotonicultora do estado (Instituto Brasileiro de Geografia e Estatística. Produção Agrícola Municipal, 1992-2002. http:/ / www.sidra. ibge.gov.br/bda, acessado em 14/Set/2004), apresentou a segunda maior prevalência de intoxicações no estado e a maior prevalência de tentativa de suicídio, por 100 mil habitantes, considerando a população rural. Uma correlação estatisticamente significativa foi encontrada na 
microrregião entre tentativa de suicídio e a produção de algodão 4 .

Uma avaliação das condições sócio-econômicas e de saúde dos cotonicultores dos municípios de Fátima do Sul e Vicentina, da microrregião de Dourados, indicou que os seus produtores tinham baixo nível de escolaridade, praticavam agricultura familiar e recebiam pouca assistência técnica 5 . Oitenta por cento dos produtores consultados apresentavam sintomas de intoxicação provocados pela exposição aos agrotóxicos.

Neste presente estudo, as notificações de intoxicação devido ao uso de agrotóxicos na microrregião de Dourados no período de 1992 a 2002 foram avaliadas, com o objetivo de subsidiar um futuro estudo de campo com os agricultores dessa região.

\section{Metodologia}

Dados sobre as populações urbanas e rurais, módulos dos estabelecimentos rurais e áreas ocupadas pelas culturas temporárias nos municípios que compõem a microrregião de Dourados (Figura 1) foram obtidos do Censo Agropecuário (Instituto Brasileiro de Geografia e Estatística. Censo Agropecuário 1996. http:/ / www. sidra.ibge.gov.br/bda/agric/default.asp?z= t\&o=11, acessado em 14/Set/2004), dos Censos Demográficos 1980, 1991 e 2000 (Instituto Brasileiro de Geografia e Estatística. Censos Demográficos 1980, 1991, 2000. http://www.sidra.ibge.gov.br/bda/tabela/listabl.asp?c $=202 \& z=$ t\&o=4, acessado em 14/Set/ 2004) e da Produção Agrícola Municipal (PAM) do IBGE (Instituto Brasileiro de Geografia e Estatística. Produção Agrícola Municipal, 1992-2002. http:// www.sidra.ibge.gov.br/bda, acessado em 14/Set/ 2004).

Dados de prevalência de intoxicação, tentativa de suicídio e óbitos relacionados a agrotóxicos de uso agrícola na microrregião, ocorridos entre janeiro de 1992 e dezembro de 2002, a idade e o sexo do indivíduo, o município e a data da ocorrência e os princípios ativos utilizados foram obtidos dos registros do Centro Integrado de Vigilância Toxicológica da Secretaria de Saúde do Estado de Mato Grosso do Sul (CIVITOX/MS). Dados, não publicados, de óbitos por suicídio, provocados por causas diversas, de acordo com a Classificação Internacional de Doenças - 10a Revisão (http:// datasus.gov.br/cid10/cid10.htm, acessado em 14/
Figura 1

Esquema dos municípios da microrregião de Dourados, Mato Grosso do Sul, Brasil.
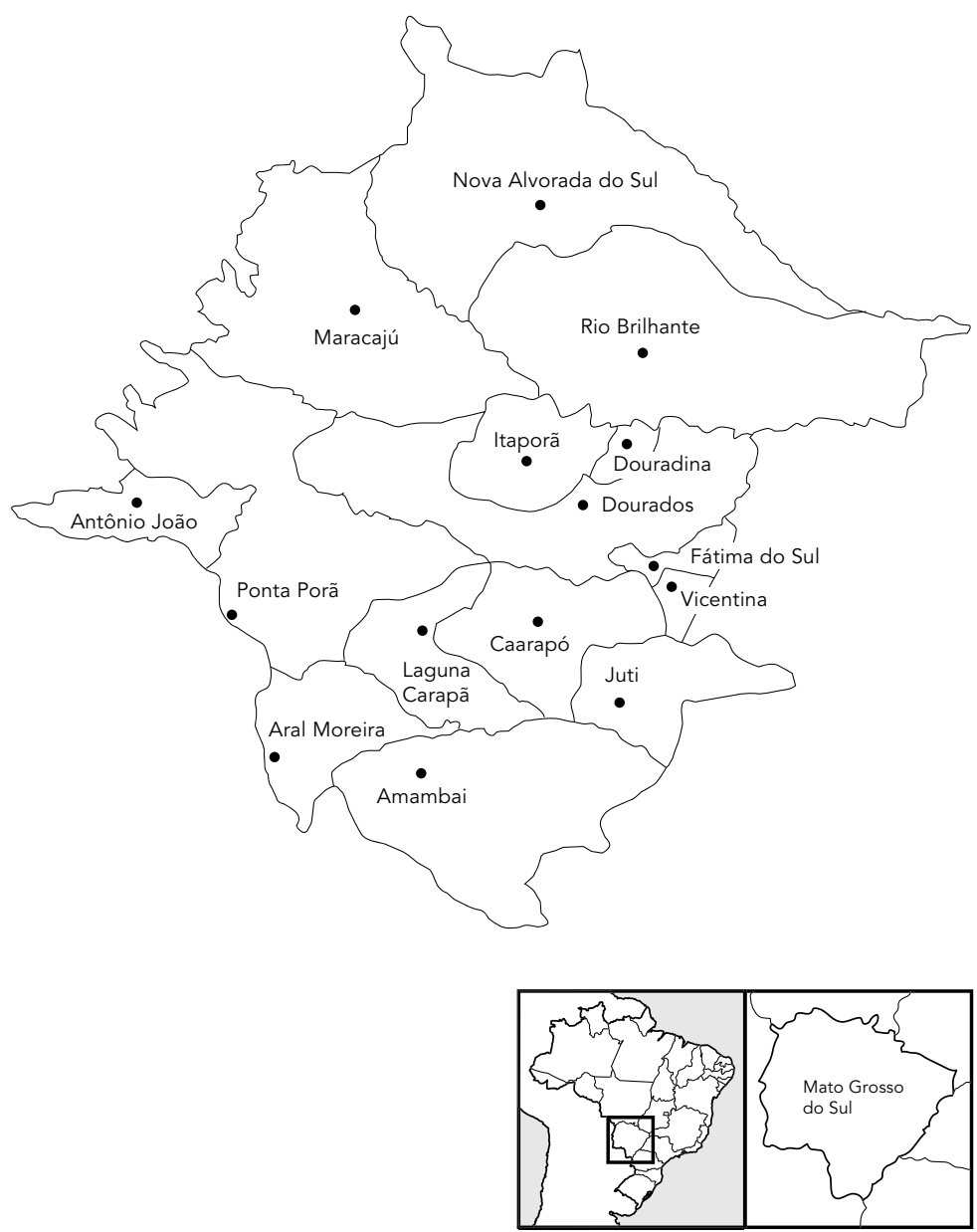

Set/2004) foram obtidos da Secretaria de Saúde do Estado de Mato Grosso do Sul. Esses dados refletem apenas parcialmente a realidade, já que, segundo estimativas do Ministério da Saúde, para cada evento de intoxicação por agrotóxico notificado, existem outros cinqüenta não notificados 6 . De todo o modo, esses números, juntamente com os fornecidos pelo IBGE, permitem traçar um panorama da intoxicação na microrregião produtora de Dourados, apontar os municípios mais críticos para futuros monitoramentos e indicar possíveis causas. 
As prevalências das intoxicações, tentativas de suicídio e óbitos foram normalizadas para 100 mil habitantes, considerados da área rural, e para a área plantada em hectares. As populações rurais dos municípios, no período de 1992/ 2002, foram obtidas com base na análise de tendência polinomial (ordem $2, \mathrm{R}^{2}>0,75$ ), baseando-se em dados dos Censos Demográficos de 1980, 1991, 2000 e do Censo Agropecuário de 1996, e a área plantada valendo-se da Produção Agrícola Municipal, no período de 1992/ 2002.

O coeficiente de determinação ( $\left.\mathrm{R}^{2}\right)$ compara valores de "y" estimados e reais, e seu valor varia entre 0 e 1 . Os valores reais das populações rurais obtidos nos censos apresentam um pico de flutuação, representado graficamente por uma curva, diante disto, o modelo mais apropriado para estimar os valores para os outros anos de interesse é o de tendência polinomial de ordem 2 , visto que foi o que proporcionou o maior valor do R2, portanto, o melhor ajuste.

As correlações estatísticas entre a prevalência de intoxicações e tentativas de suicídio provocadas pela exposição aos agrotóxicos de uso agrícola com base em dados apresentados na Tabela 1, entre a prevalência das tentativas de suicídio e a proporção da área ocupada por culturas temporárias em relação à área total do município baseando-se em dados apresenta- dos nas Tabelas 1 e 2, e finalmente as correlações entre a prevalência das intoxicações e as culturas do algodão e do feijão com base em dados apresentados nas Tabelas 2 e 3, no período considerado, encontradas neste estudo, foram determinadas pelo coeficiente de Pearson (r), dos Índices de Confiabilidade (IC95\%) e do Índice de Significância ( $\mathrm{p} \leq 0,05)$, utilizando o programa Epi Info 2000.

\section{Resultados}

A Tabela 2 mostra as características da atividade rural dos 15 municípios da microrregião de Dourados. Douradina, Dourados, Fátima do Sul e Itaporã possuem, proporcionalmente à área total do município, as maiores áreas dedicadas às culturas temporárias ( $>45,0 \%$ ). Fátima do Sul e Vicentina são os maiores produtores de algodão, com 11,0 e 14,5\% da área de culturas temporárias dedicada a essa cultura, respectivamente. Os municípios de Caarapó, Dourados, Douradina, Fátima do Sul e Itaporã são, predominantemente, agrícolas, apresentando área ocupada por culturas temporárias maior que a área com atividade pecuária $(\mathrm{A} / \mathrm{P}>1)$. Amambaí, Fátima do Sul e Vicentina possuem mais de $80,0 \%$ das propriedades com menos de 50ha, consideradas pequenas propriedades.

Prevalência das ocorrências relacionadas a agrotóxicos, por 100 mil habitantes da população rural e de suicídios com causas diversas, por 100 mil habitantes da população total, na microrregião de Dourados, Mato Grosso do Sul, Brasil, entre 1992 e 2002.

\begin{tabular}{|c|c|c|c|c|}
\hline Município & Intoxicações & $\begin{array}{c}\text { Tentativas de } \\
\text { suicídio }\end{array}$ & $\begin{array}{l}\text { Óbitos por } \\
\text { suicídios }\end{array}$ & $\begin{array}{l}\text { Suicídios causas } \\
\text { diversas (CID-10) }\end{array}$ \\
\hline Antônio João & 38,4 & 28,8 & 0,0 & 11,6 \\
\hline Amambaí & 5,1 & 9,4 & 2,6 & 19,2 \\
\hline Aral Moreira & 21,2 & 3,9 & 3,9 & 10,5 \\
\hline Caarapó & 23,6 & 23,6 & 5,5 & 18,2 \\
\hline Douradina & 12,8 & 35,8 & 30,4 & 11,5 \\
\hline Dourados & 64,5 & 58,7 & 12,2 & 10,1 \\
\hline Fátima do Sul & 39,4 & 39,4 & 10,5 & 12,1 \\
\hline Itaporã & 30,1 & 28,1 & 12,4 & 9,5 \\
\hline Juti & 6,1 & 16,8 & 16,8 & 12,4 \\
\hline Laguna Carapã & 25,1 & 33,6 & 16,8 & 21,4 \\
\hline Maracaju & 41,8 & 12,3 & 3,5 & 7,7 \\
\hline Nova Alvorada & 15,9 & 14,0 & 0,0 & 3,4 \\
\hline Ponta Porã & 43,5 & 22,1 & 8,4 & 5,1 \\
\hline Rio Brilhante & 7,7 & 9,8 & 1,6 & 5,6 \\
\hline Vicentina & 35,6 & 5,7 & 3,4 & 5,2 \\
\hline Média \pm DP & $27,4 \pm 16,7$ & $22,8 \pm 14,7$ & $8,5 \pm 8,2$ & $10,9 \pm 5,3$ \\
\hline
\end{tabular}


Características da área rural da microrregião de Dourados, Mato Grosso do Sul, Brasil, entre 1992 e 2002.

\begin{tabular}{|c|c|c|c|c|}
\hline Município & $\begin{array}{l}\text { Área de culturas } \\
\text { temporárias (ha)* }\end{array}$ & $\begin{array}{l}\text { Área de culturas } \\
\text { temporárias/área } \\
\text { do município (\%) }\end{array}$ & $\begin{array}{l}\text { Área de culturas } \\
\text { temporárias/área } \\
\text { de pastagens (\%) }\end{array}$ & $\begin{array}{l}\text { Propriedades } \\
\quad<50 \text { ha (\%) }\end{array}$ \\
\hline Antônio João & 11.419 & 10,0 & 0,8 & 42,5 \\
\hline Amanbaí & 14.558 & 3,4 & 0,8 & 90,9 \\
\hline Aral Moreira & 64.074 & 38,6 & 1,0 & 44,1 \\
\hline Caarapó & 64.667 & 30,9 & 1,3 & 71,7 \\
\hline Douradina & 15.855 & 56,3 & 1,6 & 78,7 \\
\hline Dourados & 201.431 & 49,5 & 1,6 & 70,5 \\
\hline Fátima do Sul & 15.370 & 48,6 & 1,3 & 88,5 \\
\hline Itaporã & 71,753 & 54,1 & 1,6 & 69,1 \\
\hline Juti & 4.368 & 2,7 & 0,3 & 48,8 \\
\hline Laguna Carapã & 43.482 & 25,3 & 0,7 & 37,3 \\
\hline Maracaju & 149.678 & 28,1 & 0,8 & 8,7 \\
\hline Nova Alvorada & 32.739 & 7,2 & 0,2 & 4,4 \\
\hline Ponta Porã & 152.254 & 28,4 & 0,7 & 17,5 \\
\hline Rio Brilhante & 112.746 & 28,2 & 0,9 & 13,3 \\
\hline Vicentina & 7.372 & 23,7 & 1,0 & 89,6 \\
\hline Média \pm DP & $59.339 \pm 64.480$ & $29,0 \pm 17,9$ & $1,0 \pm 0,4$ & $51,7 \pm 29,9$ \\
\hline
\end{tabular}

* Inclui algodão, arroz, cana-de-açúcar, feijão, milho, soja e trigo.

Relação entre prevalência de intoxicação e tentativa de suicídio, e áreas dedicadas às culturas de algodão e feijão em relação à área de culturas temporárias, na microrregião de Dourados, Mato Grosso do Sul, Brasil, entre 1992 e 2002.

\begin{tabular}{|c|c|c|c|c|}
\hline Município & $\begin{array}{c}\text { Intoxicação/área } \\
\text { de culturas } \\
\text { temporárias } \\
\text { (x 10-5) }\end{array}$ & $\begin{array}{c}\text { Tentativa de } \\
\text { suicídio/área } \\
\text { de culturas } \\
\text { temporárias } \\
\text { (x 10-5) }\end{array}$ & $\begin{array}{l}\text { Área de cultivo } \\
\text { de algodão/área } \\
\text { de culturas } \\
\text { temporárias } \\
(\%)\end{array}$ & $\begin{array}{c}\text { Área de cultivo } \\
\text { de feijão/área } \\
\text { de culturas } \\
\text { temporárias } \\
(\%)\end{array}$ \\
\hline Antônio João & 4,4 & 2,4 & 0,3 & 1,1 \\
\hline Amambaí & 3,4 & 6,9 & 0,7 & 0,7 \\
\hline Aral Moreira & 1,7 & 0,3 & 0,4 & 0,2 \\
\hline Caarapó & 2,3 & 2,4 & 1,4 & 3,0 \\
\hline Douradina & 1,9 & 4,0 & 0,1 & 1,8 \\
\hline Dourados & 4,4 & 4,1 & 0,3 & 1,9 \\
\hline Fátima do Sul & 9,8 & 7,8 & 11,0 & 7,9 \\
\hline Itaporã & 2,1 & 2,0 & 0,1 & 0,9 \\
\hline Juti & 2,1 & 8,3 & 6,7 & 7,6 \\
\hline Laguna Carapã & 0,7 & 0,8 & 0,2 & 0,4 \\
\hline Maracaju & 1,7 & 0,4 & 1,2 & 0,3 \\
\hline Nova Alvorada & 3,8 & 0,3 & 0,2 & 0,9 \\
\hline Ponta Porã & 2,0 & 1,0 & 3,8 & 0,7 \\
\hline Rio Brilhante & 0,4 & 0,6 & 0,5 & 0,6 \\
\hline Vicentina & 12,2 & 2,5 & 14,5 & 10,1 \\
\hline Média \pm DP & $3,5 \pm 3,3$ & $2,9 \pm 2,7$ & $2,8 \pm 4,5$ & $2,5 \pm 3,2$ \\
\hline
\end{tabular}


No total ocorreram 475 intoxicações pelo uso de agrotóxicos na microrregião de Dourados no período do estudo, correspondendo a $35,0 \%$ das intoxicações ocorridas no estado. Destas, 261 intoxicações foram do tipo acidental ou profissional, 203 tentativas de suicídios e 11 indeterminadas. Quatorze pessoas foram a óbito na microrregião em conseqüência da intoxicação e 63 pela ingestão voluntária.

A Tabela 1 mostra as prevalências de intoxicações, tentativas de suicídios e óbitos pelo uso de agrotóxicos na população da microrregião de Dourados. O Município de Dourados apresentou as maiores prevalências de intoxicações e tentativas de suicídios (64,5 e 58,7 por $100 \mathrm{mil}$ habitantes da população rural, respectivamente). Fátima do Sul apresentou a segunda maior prevalência de tentativa de suicídios $(39,4)$, Douradina a maior prevalência de óbitos pela ingestão voluntária de agrotóxicos $(30,4)$ e Laguna Carapã a maior prevalência de óbitos por causas diversas $(21,4$ por 100 mil habitantes da população total).

Correlações significativas foram encontradas entre as intoxicações e tentativas de suicídio $(\mathrm{r}=0,60 ; \mathrm{p}<0,05)$ (Tabela 1$)$ e entre tentativa de suicídio e a proporção da área ocupada por culturas temporárias em relação à área total do município - APM - $(\mathrm{r}=0,68 ; \mathrm{p}<0,05)$ (Tabelas 1 e 2).

Os municípios de Vicentina e Fátima do Sul apresentaram as maiores razões intoxicações/área culturas temporárias (12,2 x 10-5 e 9,8 x 105 , respectivamente) e Juti e Fátima do Sul as maiores razões tentativa de suicídio/área culturas temporárias $\left(8,3 \times 10^{-5}\right.$ e 7,8 x 10-5, respectivamente). Nos outros municípios, essas razões variaram entre $0,3 \times 10^{-5}$ e $6,9 \times 10^{-5}$.
Dentre as culturas temporárias cultivadas na região, correlações significativas entre intoxicação e a porcentagem da área cultivada por determinada cultura e a área total ocupada por culturas temporárias, foram encontradas somente para o feijão e o algodão com $(r=0,78 \mathrm{e}$ 0,85 , respectivamente) (Tabelas 2 e 3 ).

Das 464 ocorrências devidas à exposição voluntária ou involuntária acontecidas na microrregião, $398(85,8 \%)$ reportaram a classe do agrotóxico envolvido na intoxicação e $300(64,6 \%)$, o princípio ativo. Dentre as classes dos agrotóxicos informados nas ocorrências, destacamse os inseticidas, responsáveis por $71,2 \%$ das intoxicações e 73,8\% das tentativas de suicídio ocorridas na microrregião (Tabela 4). A maior parte dos óbitos, seja pela intoxicação $(84,6 \%)$ ou por ingestão voluntária $(91,5 \%)$, também ocorreu devido aos inseticidas. Os herbicidas são a segunda classe responsável pelas ocorrências, seguidos pelos fungicidas. Apesar de haver intoxicações e tentativas de suicídios por uso de formicida, nenhum óbito ocorreu devido a esta classe de agrotóxico.

Dentre os inseticidas responsáveis pelas intoxicações, destacam-se os organofosforados e carbamatos $(34,3 \%$ e $26,0 \%$, respectivamente) e os piretróides $(6,8 \%)$ (Tabela 5$)$. Os organofosforados foram também os inseticidas mais utilizados nas tentativas de suicídio e levaram também ao maior número de óbitos, seja por exposição involuntária (intoxicação) ou voluntária (suicídio). Os organofosforados monocrotofós e metamidofós foram responsáveis pela maioria dos registros das intoxicações e tentativas de suicídio, representando, em média, 46 e 29,0\% das ocorrências reportadas aos inseticidas, respectivamente. Mais de um composto

Prevalência das ocorrências, por classes de agrotóxicos, na microrregião de Dourados, Mato Grosso do Sul, Brasil, entre 1992 e 2002 (percentuais em relação aos reportados).

\begin{tabular}{lcccc}
\hline Classe & Intoxicações (\%) & $\begin{array}{c}\text { Óbitos por } \\
\text { intoxicação (\%) }\end{array}$ & $\begin{array}{c}\text { Tentativas de } \\
\text { suicídio (\%) }\end{array}$ & $\begin{array}{c}\text { Óbitos por } \\
\text { suicídio (\%) }\end{array}$ \\
\hline Inseticida & $161(71,2)$ & $11(84,6)$ & $127(73,8)$ & $43(91,5)$ \\
Inseticida com associação & $7(3,1)$ & $0(0,0)$ & $5(2,9)$ & $0(0,0)$ \\
Herbicida & $38(16,8)$ & $0(0,0)$ & $27(15,7)$ & $3(6,4)$ \\
Herbicida com associação & $3(1,3)$ & $0(0,0)$ & $0(0,0)$ & $0(0,0)$ \\
Fungicida & $6(2,7)$ & $2(15,4)$ & $0(0,0)$ & $0(0,0)$ \\
Formicida & $5(2,2)$ & $0(0,0)$ & $8(4,7)$ & $0(0,0)$ \\
Outros* & $6(2,7)$ & $0(0,0)$ & $5(2,9)$ & $1(2,1)$ \\
Total & $226(100,0)$ & $13(100,0)$ & $172(100,0)$ & $47(100,0)$ \\
\hline
\end{tabular}

* Acaricida, cupinicida, fumigante, larvicida, nematicida. 
Grupos químicos e ingredientes ativos dos agrotóxicos responsáveis pelas notificações, na microrregião de Dourados, Mato Grosso do Sul, Brasil, entre 1992 e 2002 (percentuais em relação aos reportados).

\begin{tabular}{|c|c|c|c|c|}
\hline $\begin{array}{l}\text { Grupo químico ou } \\
\text { ingrediente ativo }\end{array}$ & Intoxicação (\%) & $\begin{array}{c}\text { Óbitos por } \\
\text { intoxicação (\%) }\end{array}$ & $\begin{array}{l}\text { Tentativas de } \\
\text { suicídio (\%) }\end{array}$ & $\begin{array}{l}\text { Óbitos por } \\
\text { suicídios (\%) }\end{array}$ \\
\hline \multicolumn{5}{|l|}{ Inseticidas } \\
\hline Organofosforado* & $79(34,3)$ & $5(45,5)$ & $88(57,9)$ & $27(77,1)$ \\
\hline Carbamato** & $60(26,0)$ & $1(9,1)$ & $5(3,3)$ & $1(2,9)$ \\
\hline Piretróide ${ }^{\star \star \star}$ & $17(6,8)$ & $1(9,1)$ & $15(9,9)$ & $2(5,8)$ \\
\hline Organoclorado\# & $16(7,4)$ & $2(18,2)$ & $10(6,6)$ & $2(5,8)$ \\
\hline \multicolumn{5}{|l|}{ Herbicidas } \\
\hline Picloran & $4(1,7)$ & $0(0,0)$ & $5(3,3)$ & $1(2,9)$ \\
\hline Glifosato & $17(7,4)$ & $0(0,0)$ & $7(4,6)$ & $0(0,0)$ \\
\hline $2,4 \mathrm{D}$ & $13(5,2)$ & $1(9,1)$ & $6(3,9)$ & $1(2,9)$ \\
\hline Trifluralina & $11(5,7)$ & $0(0,0)$ & $1(0,7)$ & $0(0,0)$ \\
\hline Paraquat e diquat & $1(0,4)$ & $0(0,0)$ & $5(3,5)$ & $0(0,0)$ \\
\hline Outros\#\# & $12(5,2)$ & $1(9,1)$ & $10(6,6)$ & $1(2,9)$ \\
\hline Total & $230(100,0)$ & $11(100,0)$ & $152(100,0)$ & $35(100,0)$ \\
\hline
\end{tabular}

* Incluindo metamidofós, monocrotofós, malationa, clorpirifós, dimetoato, diazinona, diclorvós,

fenitrationa, paration etílico, mevinfós e profenofós.

** Incluindo carbofuran e aldicarb.

$\star \star \star$ Incluindo cipermetrina, aletrina, permetrina, deltametrina e lambda-cialotrina.

\# Incluindo aldrin, endosulfan e hexaclorociclohexano.

\#\# Incluindo metomil, tiran, fipronil, lactofen, tiabendazol, bentazona, captan, glufosinato,

fosfeto de alumínio, sulfluramida, florimuron etílico, linuron e metaloxil-M.

agrotóxico esteve envolvido em trinta e cinco notificações de intoxicações e em treze tentativas de suicídio (com ou sem óbito), razão pela qual os valores totais destas ocorrências diferem nas Tabelas 4 e 5 .

As Figuras 2, 3 e 4 apresentam a prevalência das intoxicações, tentativas de suicídio e óbitos provenientes dessas tentativas, em relação ao sexo e à faixa etária dos indivíduos. Em todas as faixas etárias, as ocorrências de intoxicação com homens são mais freqüentes (Figura 2). Nenhuma intoxicação ocorreu com mulheres entre 10 e 14 anos, entre 30 e 39 e acima de 60 anos. Dos 14 óbitos ocorridos devido à exposição involuntária (intoxicação), 10 ocorreram com homens entre 20 e 59 anos e 4 em crianças entre 1 e 9 anos.

Nenhuma tentativa de suicídio ocorreu com menores de 10 anos e, neste tipo de ocorrência, a maioria dos indivíduos entre 10 e 19 anos era do sexo feminino (Figura 3). Acima de 60 anos, somente ocorrências de tentativa de suicídio com homens foram reportadas. Nenhum indivíduo com menos de 15 anos e mulheres acima de 50 anos foram a óbito após a tentativa de suicídio (Figura 4). Na faixa etária entre 15 e 19, a razão entre tentativa de suicídio e óbito foi maior em mulheres e acima desta fai- xa foi maior em homens. A relação entre intoxicação e tentativa de suicídio em homens e mulheres foi de 8,0 e 1,0, respectivamente.

A Figura 5 mostra a prevalência das ocorrências (exposições voluntária e involuntária) ao longo do ano, no período 1992-2002. Observam-se claramente picos de ocorrência nos períodos da safra de verão (outubro a março) e inverno (principalmente junho e julho). Esta correlação, porém, não foi encontrada com as tentativas de suicídio, com índices de ocorrências menores nos meses de maio e junho.

\section{Discussão}

A agricultura é a principal atividade econômica em 5 dos 15 municípios da microrregião de Dourados (Caarapó, Douradina, Dourados, Fátima do Sul e Itaporã), caracterizados principalmente pela presença de pequenas propriedades com cultivo de culturas temporárias. Pequenas propriedades são caracterizadas pela pouca tecnologia nas práticas agrícolas, incluindo o uso de pulverizadores costais para aplicação de agrotóxicos, e pouco suporte técnico e especializado, que podem favorecer a ocorrência de intoxicações ocorridas na região 5 . 
Figura 2

Prevalência de intoxicação profissional ou acidental provocada pela exposição a agrotóxicos de uso agrícola na microrregião de Dourados, Mato Grosso do Sul, Brasil, entre 1992 e 2002.

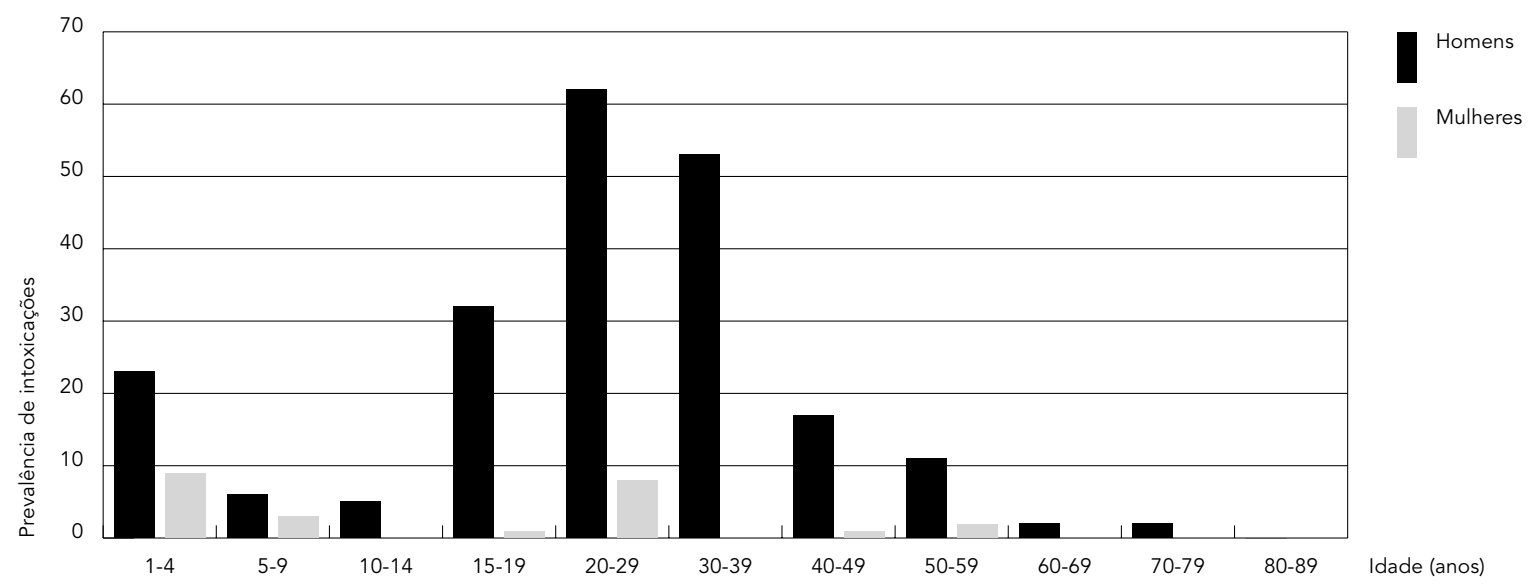

Figura 3

Prevalência de tentativas de suicídio provocadas pela ingestão de agrotóxicos de uso agrícola na microrregião de Dourados, Mato Grosso do Sul, Brasil, entre 1992 e 2002.

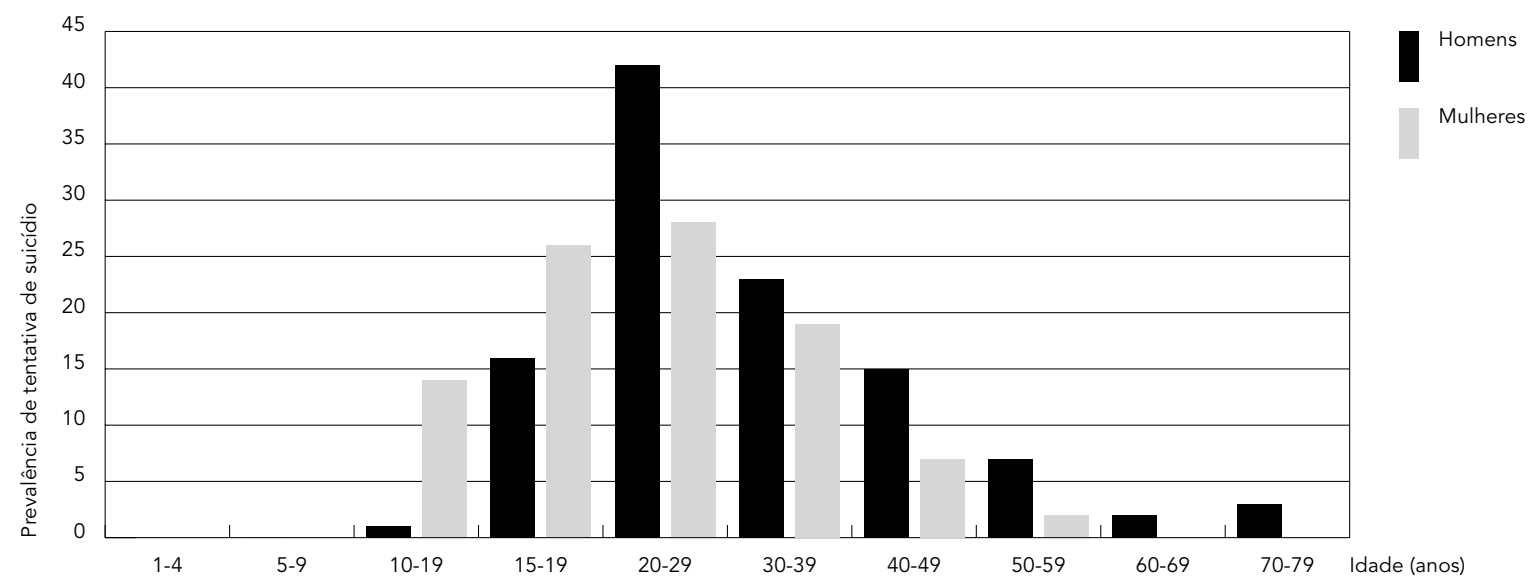


Razão entre as prevalências de tentativa de suicídio e óbito provocados pela ingestão de agrotóxicos

de uso agrícola, por idade e sexo, na microrregião de Dourados, Mato Grosso do Sul, Brasil, entre 1992 e 2002.

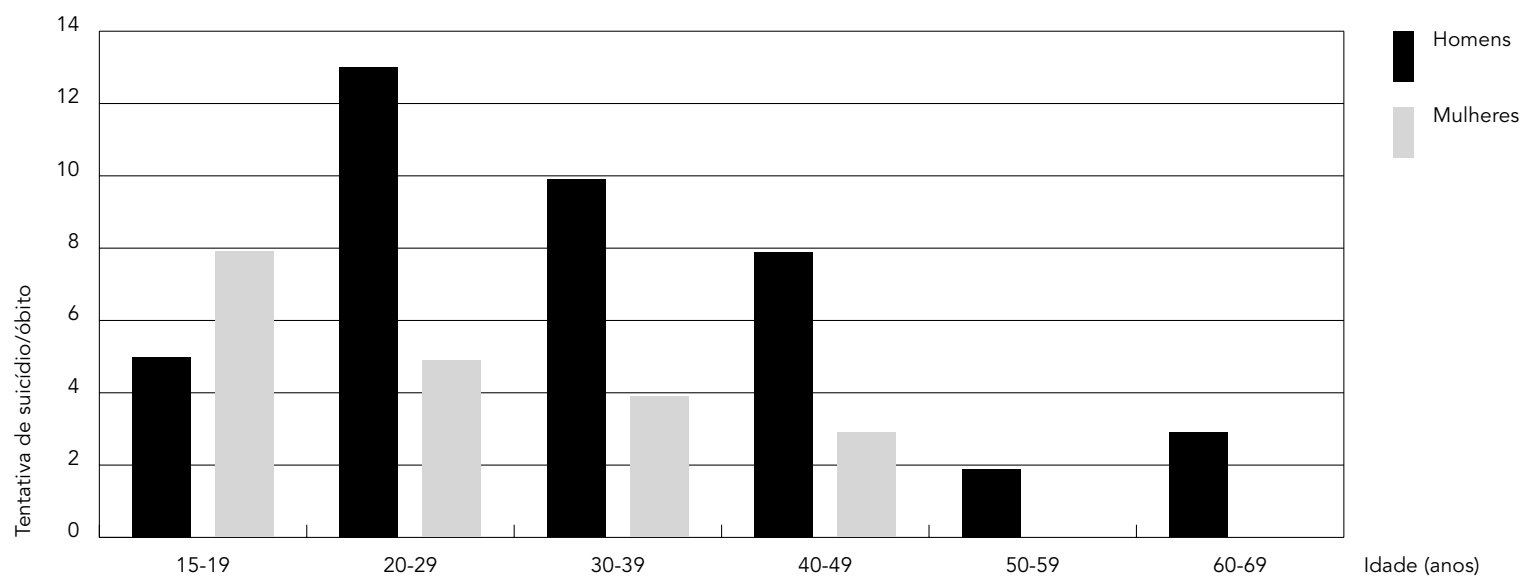

Figura 5

Sazonalidade das ocorrências provocadas pela exposição a agrotóxicos de uso agrícola na microrregião de Dourados, Mato Grosso do Sul, Brasil, entre 1992 e 2002.

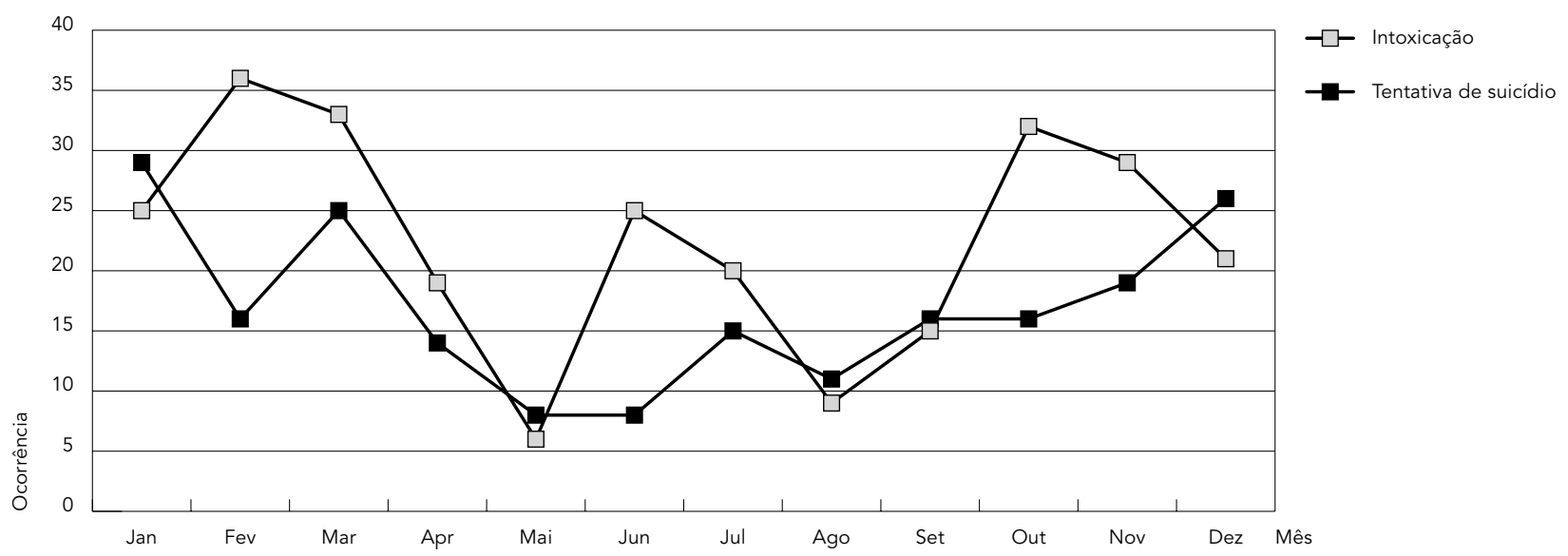


Dentre as culturas temporárias destaca-se a de algodão, que no Brasil demanda quase 80,0\% de todo o inseticida comercializado no país 7 . Os municípios de Fátima do Sul e Vicentina destacaram-se como um dos principais produtores de algodão da microrregião de Dourados, no período de 1992/2002. De fato, os inseticidas foram a principal classe de agrotóxicos envolvidos nas ocorrências, principalmente organofosforados e carbamatos, confirmando estudos conduzidos em vários países 8,9,10,11.

O perfil dos intoxicados pela exposição a agrotóxicos no campo encontrado na microrregião de Dourados, com forte predomínio de indivíduos do sexo masculino entre 20 e 39 anos, corresponde também ao encontrado no Estado ${ }^{3}$ e no país (http://www.fiocruz.br/sinitox, acessado em 14/Set/2004), refletindo diretamente a força de trabalho no campo. Com relação às tentativas de suicídio, porém, a ligação direta com a atividade ocupacional não está tão clara. Apesar de predominarem indivíduos do sexo masculino, a diferença entre a incidência em homens e mulheres não é tão significativa. A escolha da ingestão voluntária de agrotóxicos como agente letal por esses indivíduos está, provavelmente, diretamente relacionada à disponibilidade destes produtos no campo.

Se as intoxicações pela exposição involuntária podem refletir uma falta de conhecimento dos riscos dos agrotóxicos à saúde, o uso predominante dos inseticidas organofosforados na tentativa de suicídio reflete, paradoxalmente, um conhecimento real da toxicidade aguda destes compostos por esta população. Os inseticidas organofosforados inibem a enzima acetilcolinesterase, responsável pela hidrólise da acetilcolina, levando a um acúmulo deste neurotransmissor nos terminais nervosos e causando estimulação e subseqüente bloqueio dos receptores nicotínicos com efeitos no sistema nervoso 12 . Sintomas da intoxicação aguda incluem suor, salivação, lacrimejamento, fraqueza, tontura, dores e cólicas abdominais, seguidos de vômitos, dificuldade respiratória, colapso, tremores musculares, convulsões e morte 13 .

Os organofosforados causam também efeitos neurológicos retardados após a exposição aguda e como conseqüência da exposição crônica, incluindo confusão mental e fraqueza muscular 14,15. A exposição crônica a estes compostos pode levar ao desenvolvimento de sintomas de depressão 16,17,18, um fator importante nos suicídios. Farahat et al. 18, num estudo com produtores de algodão egípcios, mostrou que a exposição a estes produtos está associada à deficiência das funções neurológicas ligadas ao comportamento, bem como a prejuízos da capacidade de abstração verbal, atenção e memória. Wijngaarden 19 verificou que as atividades que envolviam o uso de agrotóxicos estavam associadas ao risco de letalidades como conseqüência de desordens mentais, principalmente em mulheres. Farias et al. 20 correlacionaram em dois municípios da serra gaúcha a prevalência de transtornos psiquiátricos menores com a incidência de casos de intoxicação aguda provocadas pela exposição aos agrotóxicos.

O predomínio de mulheres entre os indivíduos com 10 a 19 anos que tentaram suicídio encontrado neste presente estudo, também foi verificado em um estudo conduzido em Israel 21. Segundo seus autores, a principal causa é a depressão provocada por desajustes sociais e familiares, típicos dos adolescentes, mas que afeta principalmente as mulheres.

Fatores como atividade agrícola em culturas temporárias, porcentual de pequenas propriedades, prevalência de intoxicações e de tentativas de suicídio pela exposição a agrotóxicos, evidenciados pelas correlações encontradas entre prevalência de intoxicações e tentativas de suicídio, intensa atividade agrícola principalmente das culturas de algodão e feijão, indicam os municípios de Dourados, Fátima do Sul e Vicentina como críticos na microrregião de Dourados do Estado do Mato Grosso do Sul. Os municípios de Fátima do Sul e Vicentina são tradicionalmente produtores de algodão, cultura que demanda aplicação intensa de inseticidas, a principal classe de agrotóxicos envolvida nas ocorrências. O maior número de ocorrências durante a safra de verão confirma a necessidade de se avaliar estas populações neste período. 


\section{Resumo}

As notificações de intoxicações e tentativas de suicídio provocadas por agrotóxicos na microrregião de Dourados, Mato Grosso do Sul, entre 1992 e 2002, foram avaliadas baseando-se nos registros do Centro Integrado de Vigilância Toxicológica da Secretaria de Saúde do estado. Foram notificadas 475 ocorrências no período, sendo 261 intoxicações (acidental ou ocupacional), 203 tentativas de suicídio e 11 eventos de causa indeterminada. O Município de Dourados apresentou a maior prevalência de intoxicações, por 100 mil habitantes, considerando a população rural, e Fátima do Sul a segunda maior prevalência de suicídios na microrregião. Correlações significativas foram encontradas entre intoxicação e tentativa de suicídio $(r=0,60$; $p<0,05)$, e entre intoxicação e razão entre a área ocupada por culturas temporárias e área total do município $(r=0,68 ; p<0,05)$. As intoxicações ocorreram predominantemente com homens (87,0\%), mas a diferença entre tentativas de suicídio em homens e mulheres não foi acentuada (53,0 e 47,0\%, respectivamente). Os eventos ocorreram principalmente entre outubro e março, e os inseticidas organofosforados monocrotofós e metamidofós foram os principais agrotóxicos envolvidos.

Praguicidas; Suicídio; Envenenamento

\section{Colaboradores}

D. X. Pires e E. D. Caldas elaboraram o artigo. M. C. P. Recena participou da coleta e avaliação dos dados do CIVITOX/MS.

\section{Referências}

1. World Health Organization. Public health impact of pesticides used in agriculture. Geneva: World Health Organization; 1990.

2. Ecobichon DJ. Pesticides in developing countries. Toxicology 2001; 160:27-33.

3. Recena MCR, Caldas ED, Pires DX. Intoxicações por agrotóxicos na população rural do Estado de Mato Grosso do Sul no período 1992-2002. Sci Total Environ; submetido.

4. Pires DX, Caldas ED, Recena MCP. Uso de agrotóxicos e suicídios no Estado do Mato Grosso do Sul, Brasil. Cad Saúde Pública 2005; 21:598-605.

5. Gonzaga MC, Santos SO. Avaliação das condições de trabalho inerentes ao uso de agrotóxicos nos municípios de Fátima do Sul, Glória de Dourados e Vicentina - Mato Grosso do Sul. Rev Bras Saúde Ocup 1991; 72:213-5.

6. Peres F, Rozemberg B, Alves SR, Moreira JC, Oliveira-Silva JJ. Pesticide use reporting in a rural area of Rio de Janeiro State, Brazil. Rev Saúde Pública 2001; 35:564-70.

7. Fairbanks M. Defensivos agrícolas ampliam o mercado. Revista Química e Derivados 2001; 396: 398-403.

8. Senanayake N, Peires H. Mortality due to poisoning in a developing agricultural country: trends over 20 years. Hum Exp Toxicol 1995; 14:808-11.

9. Saadeh AM, Alaly MK, Farsakh NA, Ghani MA. Clinical and socio demographic future of acute carbamate and organophosphate poisoning: a study of adult patients in North Jordan. J Toxicol Clin Toxicol 1996; 34:45-51.

10. Soth T, Hosokawa M. Organophosphate and their impacts on the global environment. Neurotoxicology 2000; 21:1-4.

11. Soares W, Almeida RMVR, Moro S. Trabalho rural e fatores de risco associados ao regime de uso de agrotóxicos em Minas Gerais, Brasil. Cad Saúde Pública 2003; 19:1117-27.

12. Ecobichon DJ. Toxic effects of pesticides. In: Klaasen CD, Amdur MO, Doull J, editor. Casarett and Doull's toxicology: the basic science of poisons. New York: McGraw-Hill; 1996. p. 165-76.

13. Ames RG, Steenland K, Jenkins B, Chrislip D, Russo J. Chronic neurological sequelae to cholinesterase inhibition among agricultural pesticide applicators. Arch Environ Health 1995; 50:440-4.

14. Alavanja MCR, Hoppin JA, Kamel F. Health effects of chronicle pesticide exposure: cancer and neurotoxicity. Ann Rev Public Health 2004; 25:155-97.

15. Lidwien AM, Smith BN, van Wendel DJ, Dick H, Roshin JP, van der Hoek W. Neurological symptoms among Sri Lanka farmers occupationally exposed to acetyl cholinesterase-inhibiting insecticides. Am J Ind Med 2003; 44:254-64.

16. Scarth RD, Stalones L, Zwerling C. The incidence of depressive symptoms and risk factors among Iowa and Colorado farmers. Am J Ind Med 2000; 37:382-9.

17. Stallones L, Beseler C. Pesticide poisoning and depressive symptoms among farm residents. Ann Epidemiol 2002; 12:389-94

18. Farahat TM, Abdelrasoul GM, Amr MM, Shebl MM, Farahat FM, Anger WR. Neurobehavioural 
effects among workers occupationally exposed to organophosphorous pesticides. Occup Environ Med 2003; 60:279-86.

19. van Wijngaarden E. An exploratory investigation of suicide and occupational exposure. J Occup Environ Med 2003; 45:96-101.

20. Farias NMX, Facchini LA, Fassa ACG, Tomasi E. Processo de produção rural e saúde na serra gaúcha: um estudo descritivo. Cad Saúde Pública $2000 ; 16: 115-28$.

21. Lifshitz M, Gavrilov V. Deliberate self - poisoning in adolescents. Isr Med Assoc J 2002; 4:252-4.

Recebido em 20/Mai/2004

Versão final reapresentada em 01/Out/2004

Aprovado em 13/Out/2004 